\title{
Quality by Design Approach (QbD) for the Simultaneous Determination of Anti-Hypertensive Drugs (Candesartan, Irbesartan and Hydrochlorothiazide) by RP-HPLC
}

\begin{abstract}
A new reverse-phase liquid chromatographic technique has been developed for the separation and determination of anti-hypertensive drugs (Candesartan, Irbesartan and Hydrochlorothiazide) using QbD (Quality by Design). The present method was optimised by introducing experimental design approach to identify the chromatographic conditions where the adequate separation quality in minimal analysis duration. The relationship among independent variables and critical quality attributes is given by experimental design methodology. The segregation was consummated on Sunfire C18 type column $(150 \times 4.6 \mathrm{~mm} ; 5 \mu \mathrm{m}$ particle size) as stationary phase; $0.1 \%$ acetic acid in water: acetonitrile $(33: 77 \% \mathrm{v} / \mathrm{v}) ; 0.7351 \mathrm{ml} / \mathrm{min}$ as flow rate; detection at $225 \mathrm{~nm}$. The chromatographic efficiency was investigated for the composite effects of $\%$ organic phase and flow and finely optimized by employing central composite design. The method was validated and was found to be accurate, precise and robust. The method was thrivingly exercised with the marketed formulations.
\end{abstract}

Keywords: Hydrochlorothiazide; Irbesartan; Candesartan; Central composite design; RP-HPLC; Validation

Research Article
Volume 4 Issue 5 - 2017
Mukthinuthallapati Mathrusri Annapurna*,
Venkatesh B and Krishna Chaitanya R
Department of Pharmaceutical Analysis \& Quality Assurance,
GITAM University, India
*Corresponding author: Mukthinuthalapati Mathrusri
Annapurna, GITAM Institute of Pharmacy, GITAM University,
Rushikonda, Visakhapatnam-530045, India,
Email: mathrusri2000@yahoo.com
Received: April 26, 2017 | Published: May 05, 2017

Abbreviations: QbD: Quality by Design; CCD: Central Composite Design; IRB: Irbesartan; CST: Candesartan; HTZ: Hydrochlorothiazide; CAN: Acetonitrile; PDA: Photo Diode Array; \%RSD: Percentage Relative Standard Deviation; ICH: International Conference on Harmonization

\section{Introduction}

Sartans are used solely or in alliance with other hypertensives during hypertension therapy [1,2]. These were also used in treatment of diabetic nephropathy in patients suffering with hypertension with type 2 diabetes mellitus and also in congestive heart failure. These angiotensin II receptor antagonists are given in combinations with hydrochlorothiazide, a diuretic that is very effective in treating blood pressure [3]. In modern trends the International Conference on Harmonization (ICH) suggests implementation of Quality by design based experiments in the fields of pharmaceutical product development and also in analytical method development. Optimization of HPLC method very tangled procedure as the separation and other performance criteria depend on various independent variable parameters such as Strength of buffer, mobile phase $\mathrm{pH}$, flow rate, detection wavelength, etc. [4]. Any significant interaction between those independent variables may lead to the failure of the univariate procedure as the effect of one variable on the response may be in connection with the levels of the other variables involved in the method optimization. Chemometric approach has become a new and better concept for the RP-HPLC method optimization than the traditional approach based on fluky trial and error methodologies as there is reduction in the number of experiments there by lowering reagent consumption. The experimental design methodology explains the concomitance between the sensitivity of the independent variables and chromatographic parameters that critically attributes the method quality [5].

Irbesartan (IRB) an angiotensin-II receptor antagonist and also used for the curtailment of renal disease progression in patients with type 2 diabetes [6]. It is chemically known as 2- butyl- 3- (\{4[2- (2H- 1, 2, 3, 4- tetrazol- 5-yl) phenyl] phenyl $\}$ methyl)- 1,3diazaspiro [4.4] non- 1- en- 4- one $\left(\mathrm{C}_{25} \mathrm{H}_{28} \mathrm{~N}_{6} \mathrm{O}\right) 428.53 \mathrm{~g} / \mathrm{mol}$.

Candesartan (CST) is an angiotensin II type 1 receptor antagonist [7]. It is chemically tetrazole derivative which is chemically known as - 2- ethoxy- 1 - ( $\{4$ - [2- $(2 \mathrm{H}-1,2,3,4$ - tetrazol5- yl) phenyl] phenyl $\}$ methyl)- $1 \mathrm{H}-1,3-$ benzodiazole- 7 carboxylic acid $\left(\mathrm{C}_{24} \mathrm{H}_{20} \mathrm{~N}_{6} \mathrm{O}_{3}\right)$ with molecular weight $440.45 \mathrm{~g} / \mathrm{mol}$.

Hydrochlorothiazide (HTZ) is a thiazide diuretic [8]. Chemically it is known as 6- chloro - 1,1 -dioxo -3, 4- dihydro - $2 \mathrm{H}$ $-1,2$, 4 -benzothiadiazine -7 -sulfonamide $\left(\mathrm{C}_{7} \mathrm{H}_{8} \mathrm{ClN}_{3} \mathrm{O}_{4} \mathrm{~S}_{2}\right)$ with a molecular weight of $297.74 \mathrm{~g} / \mathrm{mol}$. The chemical structures of HTZ, IRB and CST were shown in Figure 1A-1C respectively.

Literature survey acknowledge that various methods such as LC-MS [9,10], UPLC [11], HPLC [12-17], Micro emulsion LC [18], HPTLC [19], spectrofluorometric [20] and spectrophotometric methods [21-26] were been developed for simultaneous determination of Irbesartan and Hydrochlorothiazide in biological fluids as well as pharmaceutical formulations.

Similarly, for the simultaneous determination of Candesartan and Hydrochlorothiazide in tablet dosage forms as well as in human plasma few analytical methods such as HPTLC [27], LC-MS/MS [28], UPLC-MS/MS [29], HPLC [30-40] and spectrophotometric [41-44] were developed. 
Up to our knowledge till date no method was available for simultaneous determination of these three drugs. Therefore, the main aim of the authors is to develop a chemometric-assisted RPHPLC method possessing statistically optimized chromatographic parameters with simplest mobile phase and is to validate it as per ICH guidelines [45].

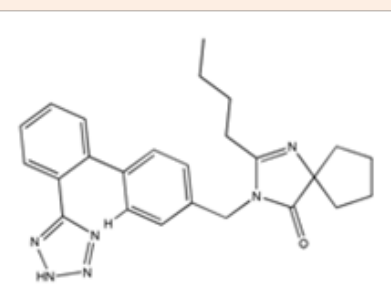

(a)

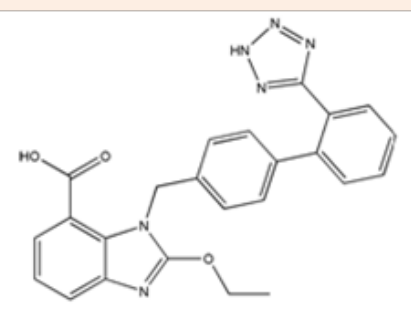

(b)

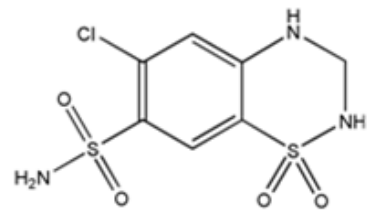

(c)

Figure 1: Chemical structures of (a) HTZ, (b) IRB (c) CST.

\section{Materials and Methods}

\section{Instrumentation}

CBM-20A/20 Alite model HPLC system of Shimadzu make, equipped with SPD M20A prominence photodiode array (PDA) detector connected to the system Dell Optiplex 790 loaded with LC Solutions v2.0 is rigged for the integrating and processing of chromatograms.

\section{Materials and reagents}

Reference standards of CST, IRB and HTZ (purity >99\%) was obtained from Sun Pharmaceutical Industries Ltd., India as gift samples. Acetonitrile, glacial Acetic acid, sodium hydroxide $(\mathrm{NaOH})$, Hydrogen peroxide $\left(\mathrm{H}_{2} \mathrm{O}_{2}\right)$ and hydrochloric acid $(\mathrm{HCl})$ were acquired from Merck (India). All chemicals used were of analytical grade and used as received. The available marketed formulations are IROVEL- ${ }^{\circledR}$ (Sun Pharmaceutical Industries Ltd., India) with a label claim: $150 \mathrm{mg} / 12.5 \mathrm{mg}$ of IRB/HTZ, and CANDESAR- $\mathrm{H}^{\circledR}$ (Ranbaxy Laboratories Ltd., India) with a label claim of $16 \mathrm{mg} / 12.5 \mathrm{mg}$ of CST/ HTZ.

$0.1 \%$ Acetic acid solution (aqueous phase) was made by meticulously transferring $1 \mathrm{ml}$ of glacial acetic acid into a $1000 \mathrm{ml}$ volumetric flask and make up the volume with HPLC grade water. The climactic solution was sonicated for half an hour and filtered. The stock solutions were prepared by accurately transferring
$25 \mathrm{mg}$ each of HTZ, IRB and CST in to different $25 \mathrm{ml}$ volumetric flasks and all the samples were dissolve using acetonitrile $(1000 \mu \mathrm{g} / \mathrm{ml})$ and obligatory supplementary dilutions were fixed from the stock solutions.

\section{Chromatographic conditions}

A reverse phase Sunfire $C_{18}$ type column (150mm length $\times$ $4.6 \mathrm{~mm}$ i.d., $5 \mu \mathrm{m}$ particle size) was used as analytical column for the separation. The analysis was fetched by: Waters make Sunfire $\mathrm{C}_{18}$ type column $(150 \mathrm{~mm} \times 4.6 \mathrm{~mm}$ i.d., $5 \mu \mathrm{m}$ particle size); $0.1 \%$ acetic acid in water and acetonitrile (33:77, v/v) as mobile phase (Isocratic mode); flow of $0.7531 \mathrm{ml} / \mathrm{min}$; UV detection at $225 \mathrm{~nm}$. All chromatographic conditions were performed at ambient room temperature $\left(25^{\circ} \mathrm{C} \pm 2^{\circ} \mathrm{C}\right)$.

\section{Calculations and software}

Chromatographic responses were taken by using LC-Solutions v1.25 which is a data acquiring software by Shimadzu. Design Expert 9.0.3 trial version (Stat-Ease Inc., Minneapolis, MN, USA) has been involved for the experimental design and the selection of the runs. The effects of parameters and their statistical interpretation employed in analytical method development were studied and calculated.

\section{Method validation}

Linearity: For the linearity studies a consecution of solutions ( $0.1-$ $200 \mu \mathrm{g} / \mathrm{ml}$ ) were projected for each drug from their respective stock solutions and $20 \mu \mathrm{l}$ of each solution was injected in to the HPLC system and the respective chromatograms were chronicled. A calibration curve was charted by considering the concentration of the drug solutions on the $\mathrm{x}$-axis and the cognate peak area on the $y$-axis and the resulting linear regression equation so attained was adapted for the assay evaluation of marketed formulations.

Precision: The method precision was valuated in terms of repeatability. The precision studies were performed by analysing the samples of HTZ, IRB and CST at three distinctive concentration levels i.e., 5, 10 and $20 \mu \mathrm{g} / \mathrm{ml}$ for HTZ and 10, 20 and $50 \mu \mathrm{g} / \mathrm{ml}$ for IRB and CST. The \% RSD of the three assay values $(n=3)$ was calculated. For inter-day precision the study was conducted on three distinctive days i.e. day 1 , day 2 and day 3 while the intraday precision study held on the same day at distinctive intervals of time.

Accuracy: The accuracy of the developed method was appraised in triplet, spiked at three pre-defined concentration levels $(80$, 100 and $120 \%$ ) for all three drugs and their percentage recoveries were calculated. The study was checked out in triplet at 9, 10 and $11 \mu \mathrm{g} / \mathrm{ml}$ for HTZ and 18, 20 and $22 \mu \mathrm{g} / \mathrm{ml}$ for IRB and CST. The percentage recoveries of all drugs were calculated in each case.

Robustness: The robustness for the developed method was performed by varying the chromatographic circumstances which compraise: flow rate $( \pm 0.1 \mathrm{ml} / \mathrm{min})$, percentage of organic phase in the mobile phase $( \pm 2 \%$ acetonitrile, $v / v)$ and wavelength $( \pm 2 \mathrm{~nm})$. Robustness of the method was reviewed in triplet at a 
concentration level of $10 \mu \mathrm{g} / \mathrm{ml}$ of each drug.

Limit of quantification and limit of detection: The limit of quantification (LOQ) and limit of detection (LOD) were based on the standard deviation of the response and the slope of the charted calibration curve $(\mathrm{n}=3)$, as described in ICH guidelines Q2 (R1) (45). LOD and LOQ majorly attributes to the sensitivity of the method.

Assay of marketed formulations: Twenty tablets of each brand of IROVEL - $\mathrm{H}^{\circledR}$ (label claim: $150 \mathrm{mg} / 12.5 \mathrm{mg}$ of IRB/HTZ), and CANDESAR - $\mathrm{H}^{\circledR}$ (label claim of $16 \mathrm{mg} / 12.5 \mathrm{mg}$ of CST/ HTZ) were procured from the local pharmacy store, weighed and crushed into fine powder. Powder equivalent to $25 \mathrm{mg}$ of IRB and CST respectively of each formulation was accurately weighed and transferred into separate $25 \mathrm{ml}$ volumetric flasks and made up to volume with mobile phase. The contents of the volumetric flasks were well sonicated about $30 \mathrm{~min}$ for the absolute dissolution of the entire drugs. The solutions were centrifuged for $15 \mathrm{mins}$ in ultra-centrifuge and the supernatant solution was collected and then filtered through $0.45 \mu \mathrm{m}$ membrane which is used as the stock for the formulations. The prerequisite dilutions were further conducted and analysed. The peak areas were recorded from the respective chromatograms.

\section{Results and Discussion}

\section{Optimization of experimental conditions}

The main aim of developing the RP-HPLC method is to simultaneously determine CST, IRB and HTZ in bulk and tablet dosage form which are separated from each other with good resolution (RS $>2.0$ ), peak shape [tailing factor $(\mathrm{TF} \leq 2)$ ] and shorter analysis time $(<10 \mathrm{~min})$ which can be achieved by modifying critical HPLC parameters. During the initiatory experimentation, several mobile phase compositions (\% organic phase) as well as flow rates were screened to study their influence on the responses. In the optimization phase, several consequential HPLC parameters whose permutation shows an impact on the separation of the three drugs were identified and to determine the optimum combination and the response pattern a face centred central composite design (CCD) with the two independent variables (\% organic phase and flow rate) each at three levels were used as shown in Table 1. A CCD-aided response surface methodology (RSM) based design of experiment was inked to acquire ideal combined effect of $\%$ organic phase (acetonitrile) and flow rate on the chromatographic responses. The pooled influence of independent variables each at triplet levels on the chromatographic responses were investigated.

From CCD-aided RSM, nine experimental runs were implemented and the influence of the above said variables at 3 level on the chromatographic responses (resolutions $\left[R S_{(H T Z-I R B)} ; R S_{(I R B-C S T)}\right]$ tailing factors $\left[T_{H T Z}, T_{I R B}\right.$ and $\left.T_{C S T}\right]$ and total analysis time [retention time of CST]) was investigated (Table 2). The resulted chromatograms from the experiment are depicted in Figure 2a-2i.

Table 1: Experimental variables and coded levels considered in the Central composite design.

\begin{tabular}{|c|c|c|c|}
\hline \multirow{2}{*}{ Variables } & \multicolumn{3}{|c|}{ Levels } \\
\hline & -1 (Low) & 0 (Medium) & 1 (High) \\
\hline \multicolumn{4}{|c|}{ Independent } \\
\hline$\%$ Organic phase (\% ACN) & 77 & 82 & 87 \\
\hline Flow rate $(\mathrm{ml} / \mathrm{min})$ & 0.6 & 0.7 & 0.8 \\
\hline \multicolumn{4}{|c|}{ Dependent } \\
\hline$R s_{(H T Z-I R B)}$ & \multicolumn{3}{|c|}{$=$ Resolution of IRB } \\
\hline$R s_{(I R B-C S T)}$ & \multicolumn{3}{|c|}{$=$ Resolution of CST } \\
\hline$T_{H T Z}$ & \multicolumn{3}{|c|}{$=$ Tailing factor of HTZ } \\
\hline$T_{I R B}$ & \multicolumn{3}{|c|}{$=$ Tailing factor of IRB } \\
\hline$T_{C S T}$ & \multicolumn{3}{|c|}{$=$ Tailing factor of CST } \\
\hline Total analysis time (min) & \multicolumn{3}{|c|}{$=$ Total run time } \\
\hline
\end{tabular}


Table 2: Experimental runs given by CCD for the two variables at triplet levels and their observed values.

Where, $R s_{(H T Z-I R B)}$ is resolution of IBR; $R s_{(I R B-C S T)}$ is resolution of CST; $T_{H T Z}$ is tailing factor of HTZ; $T_{I R B}$ is tailing factor of IRB; $T_{C S T}$ is tailing factor of CST; Totalanalysis time (min) retention time of CST.

\begin{tabular}{|c|c|c|c|c|c|c|c|c|}
\hline \multirow[b]{2}{*}{ Run } & \multicolumn{2}{|c|}{ Independent Variables } & \multicolumn{6}{|c|}{ Chromatographic Responses } \\
\hline & $\begin{array}{c}\text { \% Organic } \\
\text { phase } \\
\text { (\%ACN) }\end{array}$ & $\begin{array}{l}\text { Flow rate } \\
\text { (ml/min) }\end{array}$ & $R s_{(H T Z-I R B)}$ & $R s_{(I R B-C S T)}$ & $T_{H T Z}$ & $T_{I R B}$ & $T_{C S T}$ & Total analysis time (min) \\
\hline 1 & 82.0 & 0.7 & 9.027 & 11.944 & 1.445 & 1.567 & 1.384 & 6.975 \\
\hline 2 & 74.9 & 0.7 & 10.326 & 17.989 & 1.385 & 1.404 & 1.230 & 10.077 \\
\hline 3 & 82.0 & 0.5585 & 9.582 & 12.238 & 1.454 & 1.697 & 1.498 & 9.267 \\
\hline 4 & 82.0 & 0.8414 & 8.590 & 11.104 & 1.470 & 1.660 & 1.474 & 5.686 \\
\hline 5 & 77.0 & 0.8 & 9.568 & 16.037 & 1.378 & 1.465 & 1.324 & 7.858 \\
\hline 6 & 77.0 & 0.6 & 10.273 & 16.647 & 1.383 & 1.562 & 1.414 & 10.439 \\
\hline 7 & 87.0 & 0.6 & 7.305 & 8.402 & 1.493 & 1.563 & 1.457 & 6.158 \\
\hline 8 & 87.0 & 0.8 & 7.162 & 7.917 & 1.549 & 1.506 & 1.309 & 4.761 \\
\hline 9 & 89.1 & 0.7 & 6.340 & 6.937 & 1.634 & 1.560 & 1.224 & 4.957 \\
\hline
\end{tabular}
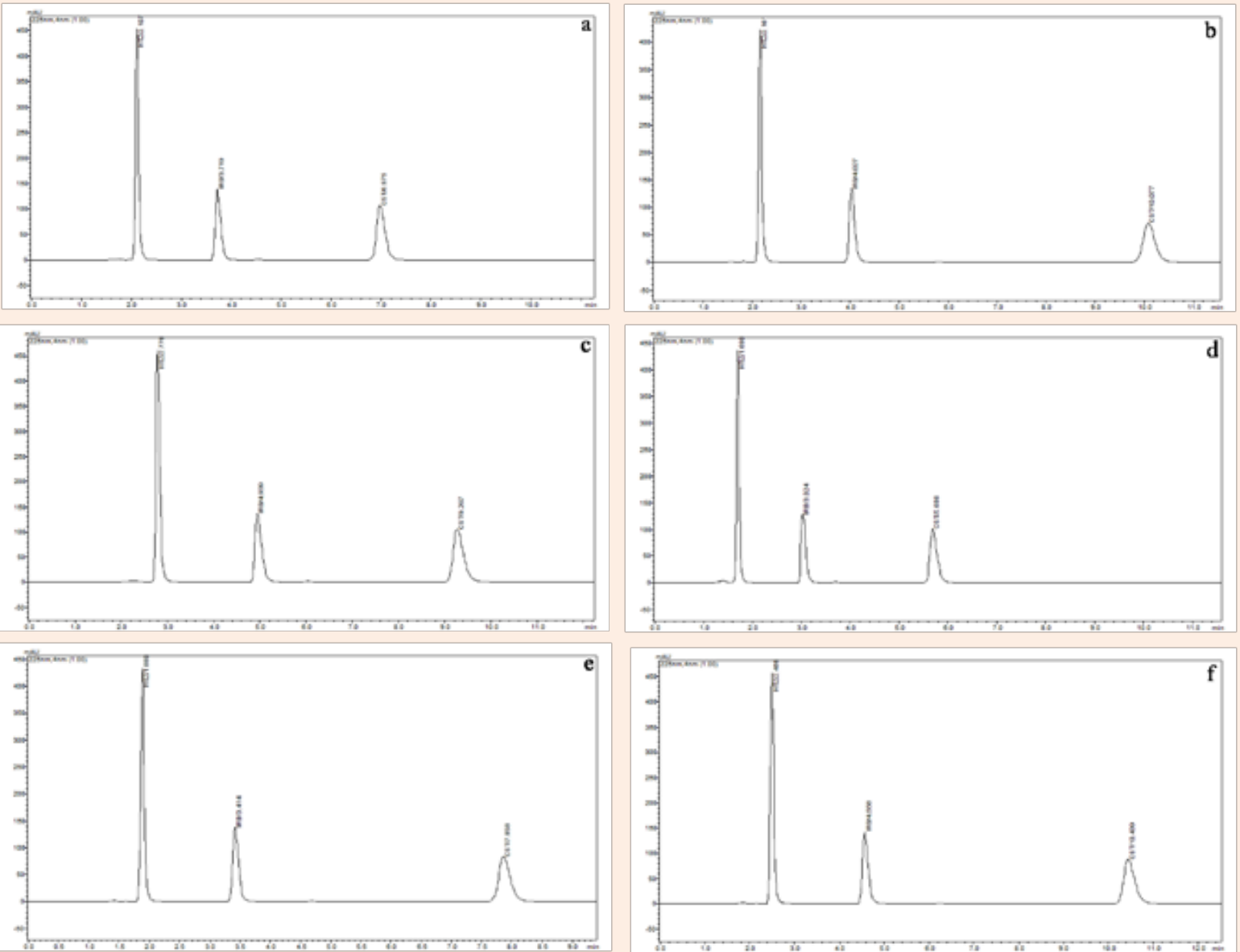

Figure 2: CCD generated trial runs and their respective chromatograms.

Citation: Annapurna MM, Venkatesh B, Chaitanya RK (2017) Quality by Design Approach (QbD) for the Simultaneous Determination of AntiHypertensive Drugs (Candesartan, Irbesartan and Hydrochlorothiazide) by RP-HPLC. J Anal Pharm Res 4(5): 00118. DOI: $10.15406 /$ japlr.2017.04.00118 

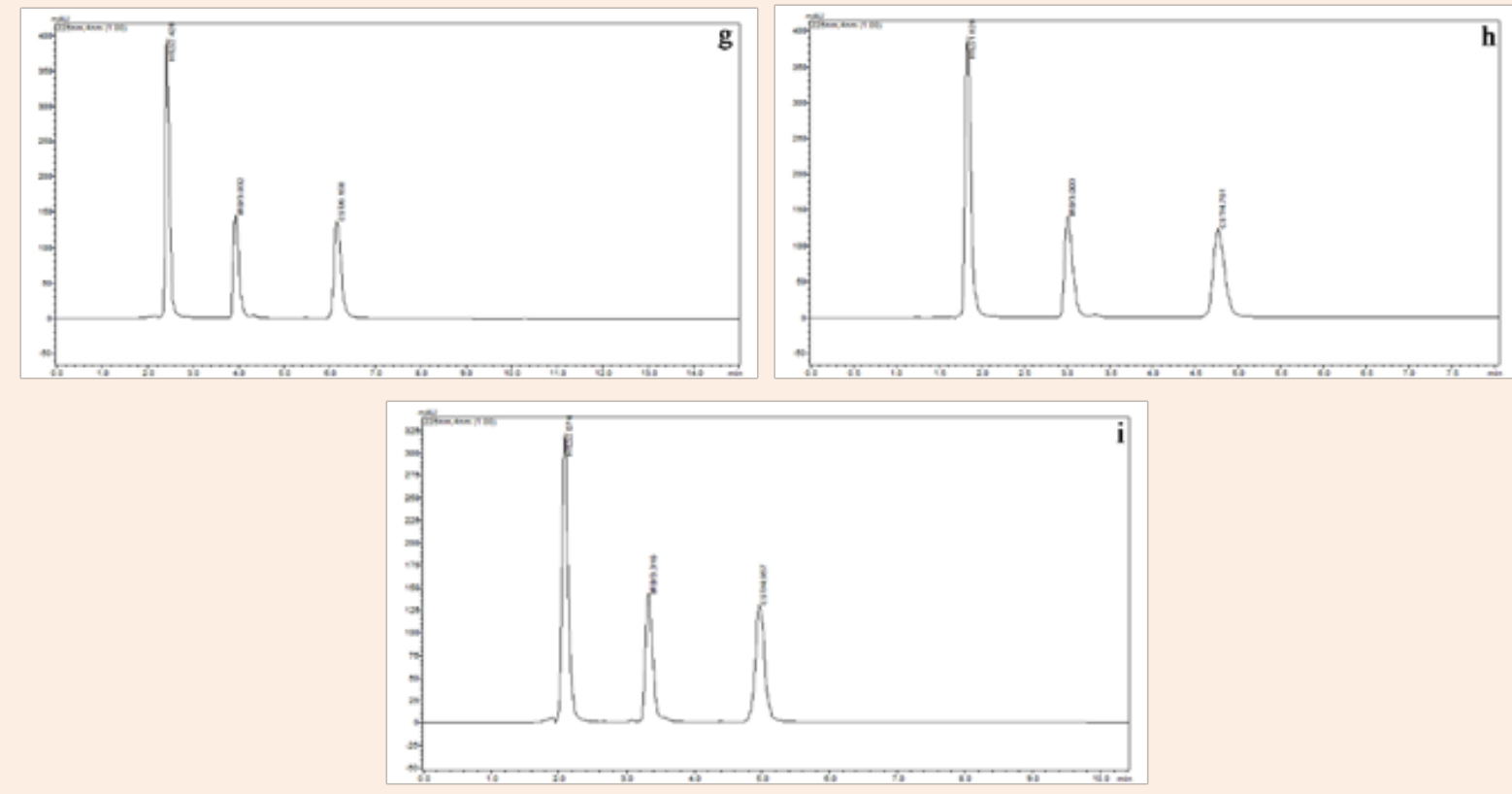

Figure 2: CCD generated trial runs and their respective chromatograms.

Design Expert 9.0 software was employed for RSM computations to produce polynomial models. In the process of analysing the selected model, they were initially evaluated for the fit summary, which gives associability between variables and the responses. The statistical parameters from the analysis of variance (ANOVA) results for this method were listed in Table 3. The values for the model were taken with no transformation. The model terms with probability (Prob $>$ F) (P value) $<0.05$ were all highly significant. The high values of the adjusted $\mathrm{R}^{2}$ for the model reveals that there is a close relation between the experimental and the predicted values of the responses there by indicating the significance and the predictableness of the model. Linear factor equation The independent variable effects and their interaction influences were studied from the computer generated polynomial regression equations (Eq. (1-6)) and given as:

$$
\begin{aligned}
& R s_{(H T Z-I R B)}=9.03-1.38 A-0.28 B+0.14 A B-0.38 A^{2}-3.644 E-003 B^{2} \\
& R s_{(I R B-C S T)}=11.94-4.00 \mathrm{~A}-0.34 B+0.031 A B+0.31 A^{2}-0.091 B^{2} \\
& T_{H T Z}=1.46+0.079 A+(9.203 E-003) B \\
& T_{I R B}=1.57+0.033 A-0.026 B+(1.000 E-002) A B-0.057 A^{2}+0.042 B^{2} \\
& T_{C S T}=1.38+(2.439 E-003) A-0.034 B-0.014 A B-0.074 A^{2}+0.20 B^{2}
\end{aligned}
$$

Total Analysistime $(\mathrm{min})=6.97-1.83 A-1.13 A-1.13 B+0.30 A B+0.22 A^{2}+0.20 B^{2}(6)$

Where, $\mathrm{A}$ is $\%$ organic phase $(\% \mathrm{ACN})$ and $\mathrm{B}$ is flow rate $(\mathrm{ml} / \mathrm{min})$.

The positive value in the equation indicates the favourable response and negative value indicates the inverse effect among the variable and the response respectively. From the equations it is clear that the \% organic phase (A) has positive effect on resolution of IRB, resolution of CST and total run time. Whereas, flow rate shows positive effect on resolution of HTZ. On the other hand, the other responses show the mixed type of response. 
Table 3: Analysis of variance for the screened chromatographic responses.

\begin{tabular}{|c|c|c|c|c|c|c|c|c|c|c|c|c|}
\hline \multirow{2}{*}{ Variables } & \multicolumn{2}{|c|}{$R s_{(H T Z-I R B)}$} & \multicolumn{2}{|c|}{$R s_{(I R B-C S T)}$} & \multicolumn{2}{|c|}{$T_{H T Z}$} & \multicolumn{2}{|c|}{$T_{I R B}$} & \multicolumn{2}{|c|}{$T_{C S T}$} & \multicolumn{2}{|c|}{ Total analysis time (min) } \\
\hline & $\mathbf{F}$ & $\mathbf{P}$ & $\mathbf{F}$ & $\mathbf{P}$ & $\mathbf{F}$ & $\mathbf{P}$ & $\mathbf{F}$ & $\mathbf{P}$ & $\mathbf{F}$ & $\mathbf{P}$ & $\mathbf{F}$ & $\mathbf{P}$ \\
\hline Model & 287.08 & $<0.0001$ & 1084.06 & $<0.0001$ & 31.61 & $<0.0001$ & 6.47 & 0.0148 & 17.85 & 0.0007 & 236.34 & $<0.0001$ \\
\hline $\begin{array}{c}\text { A- } \% \\
\text { Organic } \\
\text { phase }\end{array}$ & 1288.15 & $<0.0001$ & 5349.91 & $<0.0001$ & 62.38 & $<0.0001$ & 5.20 & 0.0566 & 0.054 & 0.8223 & 834.19 & $<0.0001$ \\
\hline B-Flow rate & 53.82 & 0.0002 & 38.06 & 0.0005 & 0.84 & 0.3800 & 3.21 & 0.1164 & 10.55 & 0.0141 & 319.15 & $<0.0001$ \\
\hline $\mathrm{AB}$ & 6.70 & 0.0360 & 0.16 & 0.6982 & - & - & 0.24 & 0.6384 & 0.96 & 0.3598 & 10.94 & 0.0130 \\
\hline $\mathrm{A}^{2}$ & 85.45 & $<0.0001$ & 27.13 & 0.0012 & - & - & 13.42 & 0.0080 & 43.05 & 0.0003 & 10.78 & 0.0134 \\
\hline $\mathrm{B}^{2}$ & 0.00785 & 0.9319 & 2.39 & 0.1664 & - & - & 7.29 & 0.0306 & 24.79 & 0.0016 & 8.91 & 0.0204 \\
\hline Adj R ${ }^{2 *}$ & \multicolumn{2}{|c|}{0.9917} & \multicolumn{2}{|c|}{0.9978} & \multicolumn{2}{|c|}{0.8361} & \multicolumn{2}{|c|}{0.6950} & \multicolumn{2}{|c|}{0.8753} & \multicolumn{2}{|c|}{0.9899} \\
\hline $\begin{array}{c}\text { Adeq. } \\
\text { Precision** }\end{array}$ & \multicolumn{2}{|c|}{55.926} & \multicolumn{2}{|c|}{107.664} & \multicolumn{2}{|c|}{16.441} & \multicolumn{2}{|c|}{10.099} & \multicolumn{2}{|c|}{15.443} & \multicolumn{2}{|c|}{48.656} \\
\hline
\end{tabular}

F - Fisher ratio; P - Probability.

The perturbation plots (Figure 3a-3f) as well as the threedimensional (3D) response surface plots (Figure 4a-4f) are very useful for studying the interactions effects of the variables on the responses. The relation between the response variables (i.e., $R s_{(H T Z-I R B)} ; R s_{(I R B-C S T)} ; T_{I R B}$ and $T_{C S T} ; \quad$ Total Analysistime and the independent variables is quadratic while in case of $T_{H T Z}$ it is linear.

The final composition independent variables for the optimization of the HPLC method was achieved by conciliating the various responses (Table 4) to obtain better resolution among the peaks with good tailing factor and minimum analysis time. The bar graph for the desirability in the optimization was shown in Figure 5. Whereas, the desirability ramp for this method was shown in Figure 6 in which the limits for the variables and the desirability criteria were clearly shown. The graphical examination of the desirability was:

Percentage Predicted Error $(P . E)=\frac{\text { Observed }- \text { Predicted }}{\text { Predicted }} \times 100$
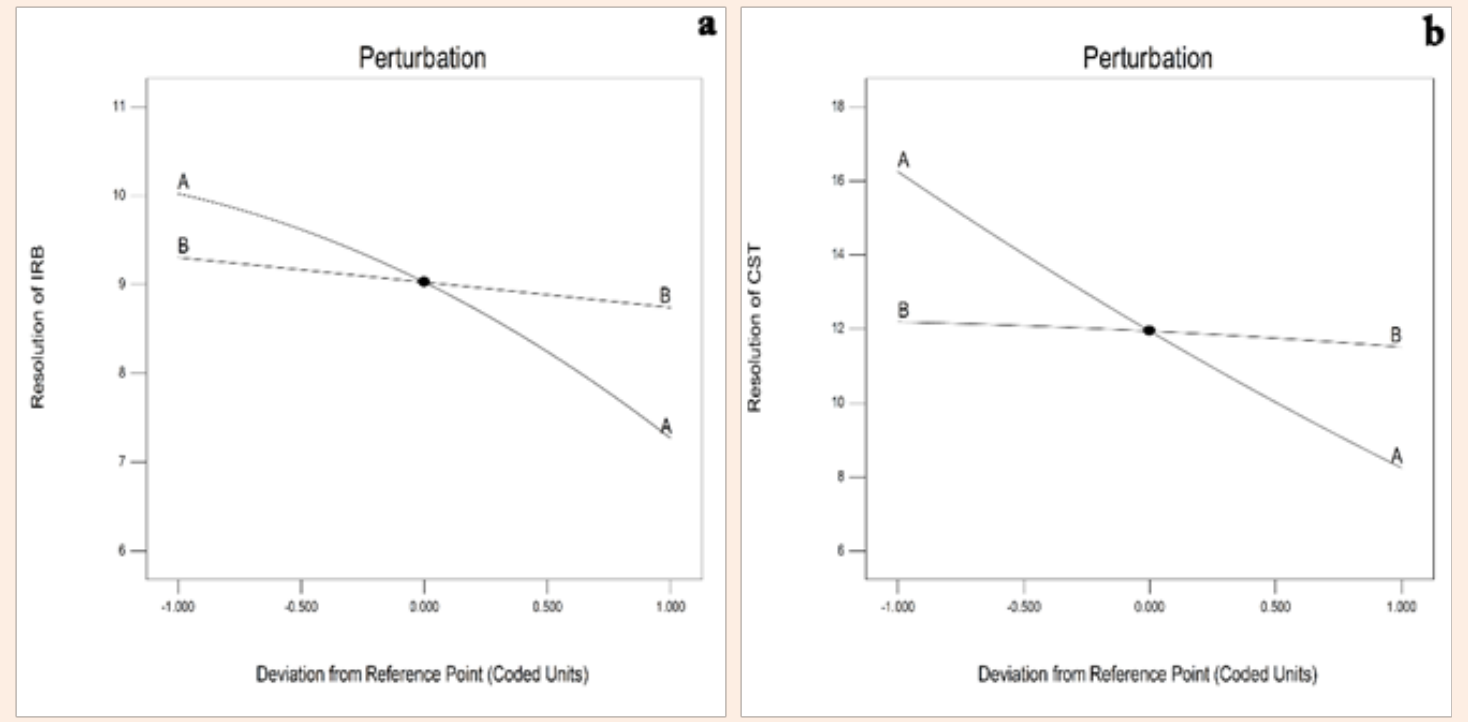

Figure 3: Perturbation plots representing the effect of $\%$ organic phase (A) and flow rate (B) on (a) $R_{(\text {(HTZ-IRB) }}\left(\right.$ b) $\operatorname{Rs}_{\text {(IRB-CST) }}(c) T_{\text {HTZ }}(d) T_{\text {IRB }}$ (e) $\mathrm{T}_{\text {CST }}$ (f) Total analysis time.
Citation: Annapurna MM, Venkatesh B, Chaitanya RK (2017) Quality by Design Approach (QbD) for the Simultaneous Determination of AntiHypertensive Drugs (Candesartan, Irbesartan and Hydrochlorothiazide) by RP-HPLC. J Anal Pharm Res 4(5): 00118. DOI: $10.15406 /$ japlr.2017.04.00118 

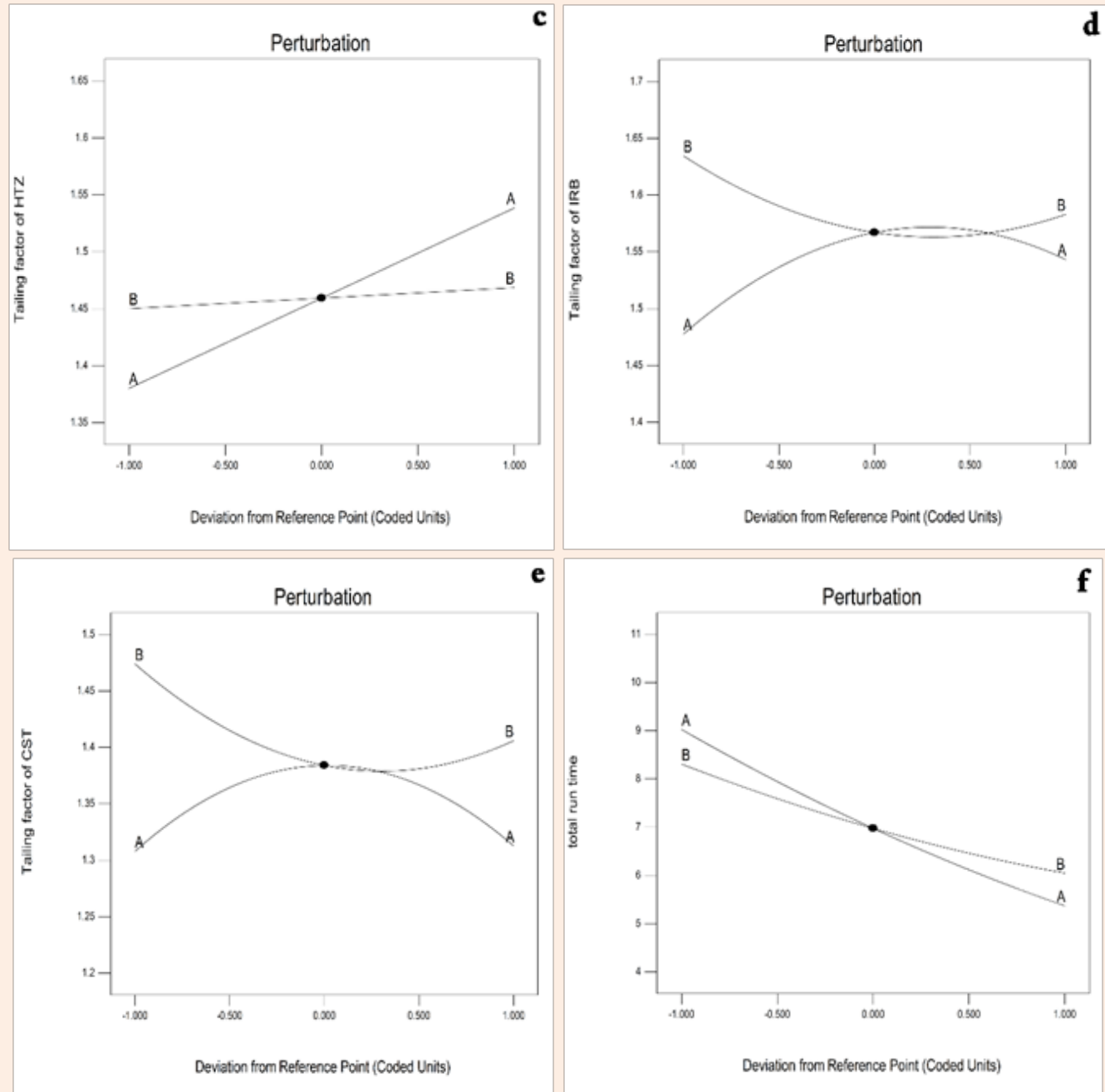

Figure 3: Perturbation plots representing the effect of \% organic phase (A) and flow rate (B) on (a) $R_{(\text {(HTZ-IRB) }}$ (b) $R_{\text {(IRB-CST) }}$ (c) $T_{\text {HTZ }}$ (d) $T_{\text {IRB }}$ (e) $\mathrm{T}_{\text {CST }}$ (f) Total analysis time.
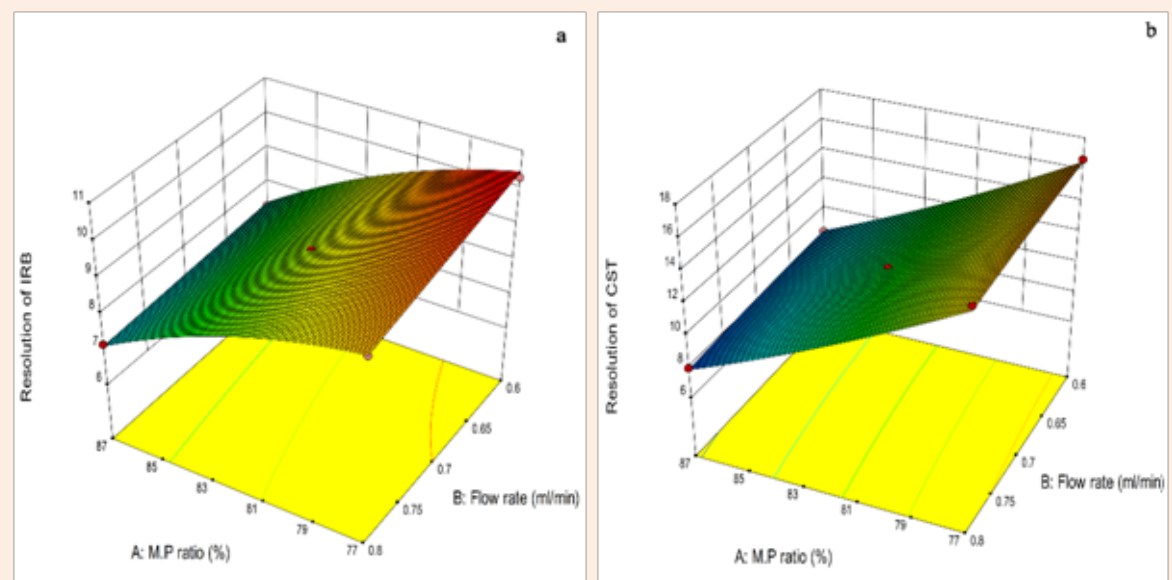

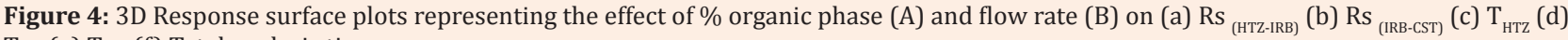
$\mathrm{T}_{\mathrm{IRB}}(\mathrm{e}) \mathrm{T}_{\mathrm{CST}}$ (f) Total analysis time.

Citation: Annapurna MM, Venkatesh B, Chaitanya RK (2017) Quality by Design Approach (QbD) for the Simultaneous Determination of AntiHypertensive Drugs (Candesartan, Irbesartan and Hydrochlorothiazide) by RP-HPLC. J Anal Pharm Res 4(5): 00118. DOI: $10.15406 /$ japlr.2017.04.00118 

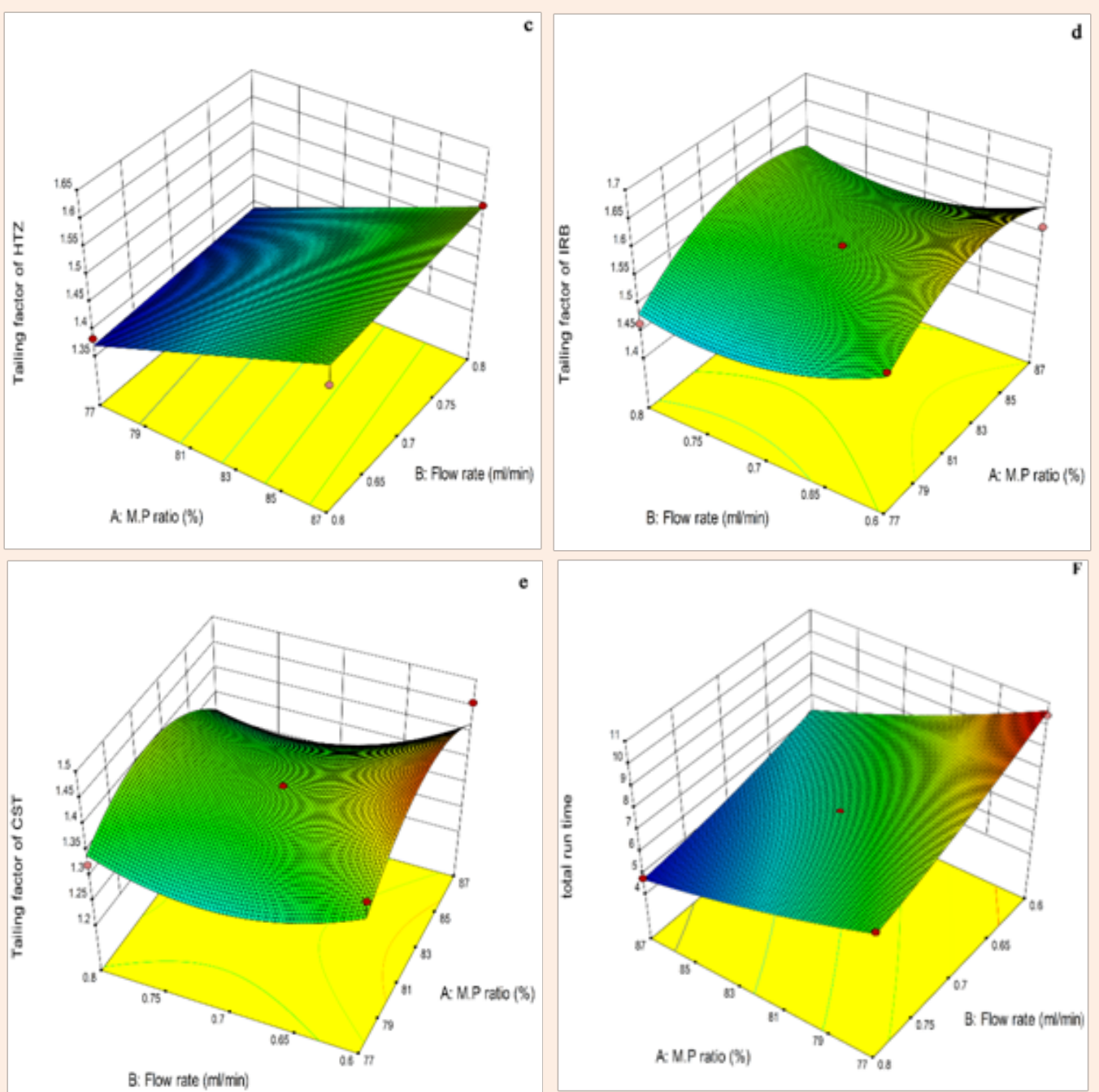

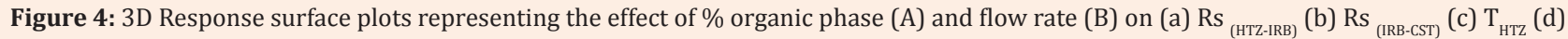
$\mathrm{T}_{\text {IRB }}(\mathrm{e}) \mathrm{T}_{\mathrm{CST}}(\mathrm{f})$ Total analysis time.

Table 4: Desirability criteria for optimized individual responses.

\begin{tabular}{|c|c|c|c|}
\hline Name & Goal & Lower Limit & Upper Limit \\
\hline$R s_{(H T Z-I R B)}$ & maximize & 6.34 & 10.326 \\
\hline$R s_{(I R B-C S T)}$ & maximize & 6.937 & 17.989 \\
\hline$T_{H T Z}$ & minimize & 1.378 & 1.634 \\
\hline$T_{C S T}$ & minimize & 1.404 & 1.697 \\
\hline$T_{C S T}$ & minimize & 1.224 & 1.498 \\
\hline Total analysis time $(\mathrm{min})$ & minimize & 4.761 & 10.439 \\
\hline
\end{tabular}

Citation: Annapurna MM, Venkatesh B, Chaitanya RK (2017) Quality by Design Approach (QbD) for the Simultaneous Determination of AntiHypertensive Drugs (Candesartan, Irbesartan and Hydrochlorothiazide) by RP-HPLC. J Anal Pharm Res 4(5): 00118. DOI: 10.15406/japlr.2017.04.00118 


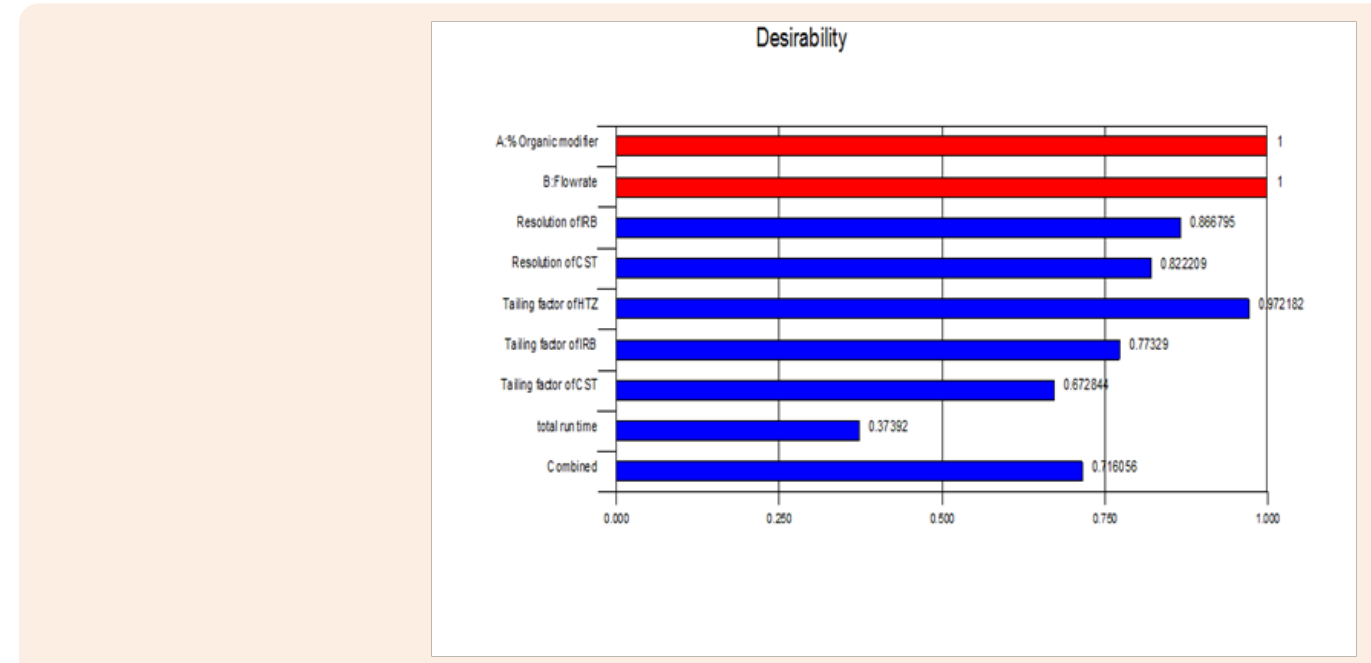

Figure 5: The desirability bar graph for the responses.

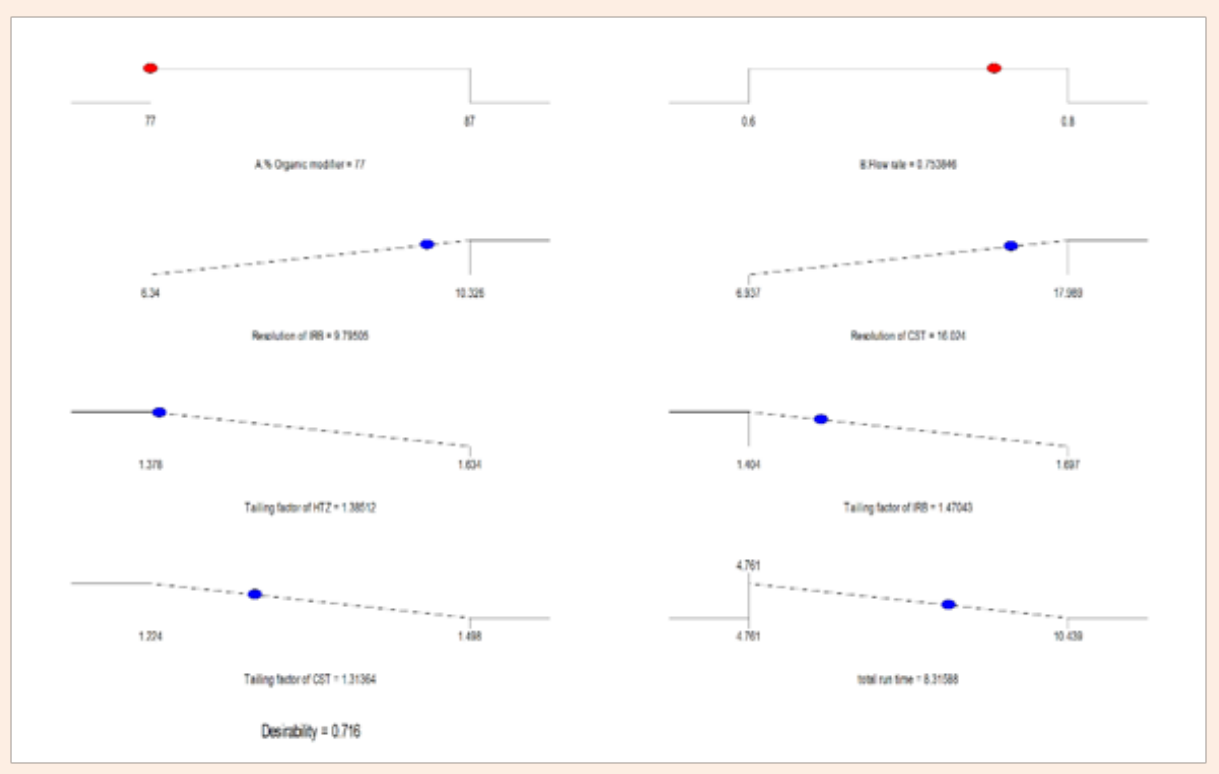

Figure 6: The desirability ramp representing the optimization of the independent variables for the better responses

Total 10 runs are given for the design expert software having better desirability which were experimented and the percentage prediction error (P.E) were calculated as per Eq. 7 and shown in Table 5. The run for which the mean percentage prediction error is least compared to the other runs is concluded as the desired method.
From this a combination of $0.1 \%$ acetic acid and acetonitrile (33:77, v/v) as mobile phase (Isocratic mode) with a flow of $0.7531 \mathrm{ml} / \mathrm{min}$ achieves the desirable responses. At this condition, $R S_{(H T Z-I R B)}$ of 10.332, $R S_{(I R B-C S T)}$ of $16.065, T_{I R B}$ of $1.365, T_{I R B}$ of $1.326, T_{C S T}$ of 1.329 , and total analysis time of 8.654 were observed and the chromatograph was shown in Figure 7. 
Table 5: Table for optimization.

\begin{tabular}{|c|c|c|c|c|c|c|c|}
\hline Solution & $\begin{array}{c}\% \text { Organic } \\
\text { Phase } \\
(\% \text { ACN) }\end{array}$ & $\begin{array}{l}\text { Flow Rate } \\
\text { (ml/min) }\end{array}$ & Responses & $\begin{array}{l}\text { Predicted } \\
\text { Values }\end{array}$ & $\begin{array}{c}\text { Observed } \\
\text { Values }\end{array}$ & PE & $\begin{array}{c}\text { Mean } \\
\text { PE }\end{array}$ \\
\hline \multirow{6}{*}{1} & \multirow{6}{*}{77.000} & \multirow{6}{*}{0.7599} & $R s_{(H T Z-I R B)}$ & 9.769 & 9.89 & 1.237 & \multirow{6}{*}{2.666} \\
\hline & & & $R s_{(I R B-C S T)}$ & 15.995 & 15.916 & -0.496 & \\
\hline & & & $T_{H T Z}$ & 1.386 & 1.369 & -1.204 & \\
\hline & & & $T_{I R B}$ & 1.471 & 1.516 & 3.050 & \\
\hline & & & $T_{C S T}$ & 1.316 & 1.459 & 10.839 & \\
\hline & & & Total analysis time (min) & 8.243 & 8.455 & 2.570 & \\
\hline \multirow{6}{*}{2} & \multirow{6}{*}{77.000} & \multirow{6}{*}{0.7607} & $R s_{(H T Z-I R B)}$ & 9.766 & 9.829 & 0.645 & \multirow{6}{*}{2.162} \\
\hline & & & $R s_{(I R B-C S T)}$ & 15.992 & 15.896 & -0.600 & \\
\hline & & & $T_{H T Z}$ & 1.386 & 1.370 & -1.136 & \\
\hline & & & $T_{I R B}$ & 1.471 & 1.492 & 1.411 & \\
\hline & & & $T_{C S T}$ & 1.317 & 1.455 & 10.506 & \\
\hline & & & Total analysis time (min) & 8.234 & 8.411 & 2.144 & \\
\hline \multirow{6}{*}{3} & \multirow{6}{*}{77.000} & \multirow{6}{*}{0.7587} & $R s_{(H T Z-I R B)}$ & 9.775 & 9.926 & 1.549 & \multirow{6}{*}{2.673} \\
\hline & & & $R S_{(I R B-C S T)}$ & 16.001 & 16.040 & 0.241 & \\
\hline & & & $T_{H T Z}$ & 1.386 & 1.376 & -0.690 & \\
\hline & & & $T_{I R B}$ & 1.471 & 1.508 & 2.518 & \\
\hline & & & $T_{C S T}$ & 1.316 & 1.440 & 9.445 & \\
\hline & & & Total analysis time (min) & 8.258 & 8.504 & 2.976 & \\
\hline \multirow{6}{*}{4} & \multirow{6}{*}{77.000} & \multirow{6}{*}{0.7571} & $R s_{(H T Z-I R B)}$ & 9.781 & 10.018 & 2.422 & \multirow{6}{*}{2.171} \\
\hline & & & $R s_{(I R B-C S T)}$ & 16.009 & 16.128 & 0.745 & \\
\hline & & & $T_{H T Z}$ & 1.385 & 1.382 & -0.247 & \\
\hline & & & $T_{I R B}$ & 1.471 & 1.467 & -0.256 & \\
\hline & & & $T_{C S T}$ & 1.315 & 1.408 & 7.070 & \\
\hline & & & Total analysis time (min) & 8.277 & 8.549 & 3.292 & \\
\hline
\end{tabular}




\begin{tabular}{|c|c|c|c|c|c|c|c|}
\hline \multirow{6}{*}{5} & \multirow{6}{*}{77.000} & \multirow{6}{*}{0.7564} & $R s_{(H T Z-I R B)}$ & 9.784 & 10.076 & 2.982 & \multirow{6}{*}{1.813} \\
\hline & & & $R s_{(I R B-C S T)}$ & 16.012 & 16.009 & -0.020 & \\
\hline & & & $T_{H T Z}$ & 1.385 & 1.376 & -0.675 & \\
\hline & & & $T_{I R B}$ & 1.471 & 1.446 & -1.678 & \\
\hline & & & $T_{C S T}$ & 1.315 & 1.405 & 6.868 & \\
\hline & & & Total analysis time (min) & 8.285 & 8.567 & 3.399 & \\
\hline \multirow{6}{*}{6} & \multirow{6}{*}{77.000} & \multirow{6}{*}{0.7642} & $R s_{(H T Z-I R B)}$ & 9.751 & 9.75 & -0.010 & \multirow{6}{*}{1.402} \\
\hline & & & $R s_{(I R B-C S T)}$ & 15.975 & 15.962 & -0.081 & \\
\hline & & & $T_{H T Z}$ & 1.386 & 1.366 & -1.448 & \\
\hline & & & $T_{I R B}$ & 1.472 & 1.457 & -1.006 & \\
\hline & & & $T_{C S T}$ & 1.318 & 1.437 & 8.992 & \\
\hline & & & Total analysis time (min) & 8.193 & 8.354 & 1.964 & \\
\hline \multirow{6}{*}{7} & \multirow{6}{*}{77.000} & \multirow{6}{*}{0.7548} & $R s_{(H T Z-I R B)}$ & 9.791 & 10.216 & 4.341 & \multirow{6}{*}{1.123} \\
\hline & & & $R s_{(I R B-C S T)}$ & 16.020 & 16.060 & 0.252 & \\
\hline & & & $T_{H T Z}$ & 1.385 & 1.368 & -1.242 & \\
\hline & & & $T_{I R B}$ & 1.471 & 1.391 & -5.407 & \\
\hline & & & $T_{C S T}$ & 1.314 & 1.379 & 4.944 & \\
\hline & & & Total analysis time (min) & 8.304 & 8.624 & 3.848 & \\
\hline \multirow{6}{*}{$8^{*}$} & \multirow{6}{*}{77.000} & \multirow{6}{*}{0.7531} & $R s_{(H T Z-I R B)}$ & 9.798 & 10.332 & 5.447 & \multirow{6}{*}{-0.074} \\
\hline & & & $R s_{(I R B-C S T)}$ & 16.028 & 16.065 & 0.233 & \\
\hline & & & $T_{H T Z}$ & 1.385 & 1.365 & -1.448 & \\
\hline & & & $T_{I R B}$ & 1.470 & 1.326 & -9.818 & \\
\hline & & & $T_{C S T}$ & 1.313 & 1.329 & 1.193 & \\
\hline & & & Total analysis time (min) & 8.325 & 8.654 & 3.950 & \\
\hline
\end{tabular}




\begin{tabular}{|c|c|c|c|c|c|c|c|}
\hline \multirow{6}{*}{9} & \multirow{6}{*}{77.000} & \multirow{6}{*}{0.7735} & $R s_{(H T Z-I R B)}$ & 9.711 & 9.45 & -2.688 & \multirow{6}{*}{0.751} \\
\hline & & & $R s_{(I R B-C S T)}$ & 15.929 & 15.844 & -0.532 & \\
\hline & & & $T_{H T Z}$ & 1.387 & 1.366 & -1.509 & \\
\hline & & & $T_{I R B}$ & 1.474 & 1.466 & -0.532 & \\
\hline & & & $T_{C S T}$ & 1.324 & 1.429 & 7.945 & \\
\hline & & & Total analysis time (min) & 8.086 & 8.233 & 1.821 & \\
\hline \multirow{6}{*}{10} & \multirow{6}{*}{77.000} & \multirow{6}{*}{0.7149} & $R s_{(H T Z-I R B)}$ & 9.960 & 10.839 & 8.822 & \multirow{6}{*}{0.569} \\
\hline & & & $R s_{(I R B-C S T)}$ & 16.192 & 16.149 & -0.265 & \\
\hline & & & $T_{H T Z}$ & 1.382 & 1.369 & -0.907 & \\
\hline & & & $T_{I R B}$ & 1.473 & 1.405 & -4.630 & \\
\hline & & & $T_{C S T}$ & 1.306 & 1.275 & -2.394 & \\
\hline & & & Total analysis time (min) & 8.817 & 9.063 & 2.786 & \\
\hline
\end{tabular}

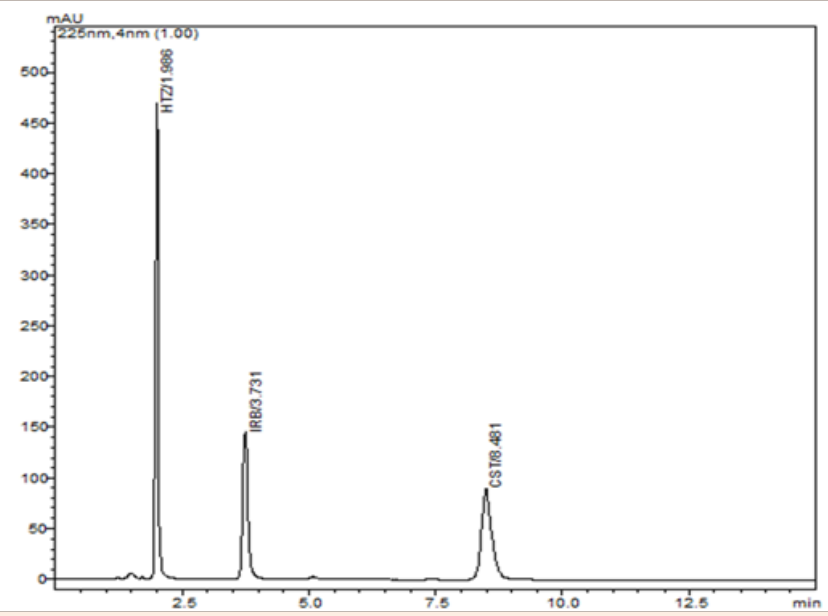

Figure 7: Typical chromatogram of Standard of HTZ, IRB and CST.

\section{Method validation}

The method was validated for system suitability, linearity, accuracy, precision, limit of detection (LOD), limit of quantitation (LOQ), selectivity and robustness (ICH guidelines, 2005).

\section{Linearity}

HTZ, IRB and CST follows linearity over a concentration range of $0.01-60 \mu \mathrm{g} / \mathrm{ml}, 0.05-120 \mu \mathrm{g} / \mathrm{ml}$ and $0.05-100 \mu \mathrm{g} / \mathrm{ml}$ respectively
(Table 6) with \% RSD 0.11-0.45, 0.08-0.42 and 0.10-0.65 for HTZ, IRB and CST respectively. The chromatographic responses of individual samples were shown in Figure 8C-8E respectively for HTZ, IRB and CST respectively. The linear regression equations were found to be $\mathrm{y}=198986 \mathrm{x}-11128\left(\mathrm{r}^{2}=0.9999\right), \mathrm{y}=100726 \mathrm{x}-$ $5887.5\left(r^{2}=0.9997\right) y=117644 x+27207\left(r^{2}=0.9999\right)$ for HTZ, IRB and CST respectively. The limit of detection (LOD) and limit of quantitation (LOQ) of each drugs were shown in Table 6. 
Table 6: Linear regression data for the calibration curve.

\begin{tabular}{|c|c|c|c|}
\hline \multirow{2}{*}{ Statistical Parameters } & \multicolumn{3}{|c|}{ Data* } \\
\cline { 2 - 4 } & HTZ & IRB & CST \\
\hline Linearity range $(\mu \mathrm{g} / \mathrm{ml})$ & $0.01-60$ & $0.05-120$ & $0.05-100$ \\
\hline Correlation coefficient $\left(\mathrm{R}^{2}\right)$ & 0.9999 & 0.9997 & 0.9999 \\
\hline Slope of curve & 198986 & 100726 & 117644 \\
\hline Intercept of curve & 11128 & 5887.5 & 27207 \\
\hline
\end{tabular}

*Mean of three replicates.

\section{Precision}

The intra-day precision of the method was established by assaying the samples of HTZ, IRB and CST at three different concentration levels i.e., 5,10 and $20 \mu \mathrm{g} / \mathrm{ml}$ for HTZ and 10, 20 and $50 \mu \mathrm{g} / \mathrm{ml}$ for IRB and CST on the same day. The inter-day precision was calculated by assaying the samples of HTZ, IRB and CST at three different concentration levels i.e., 5,10 and $20 \mu \mathrm{g} / \mathrm{ml}$ for HTZ and 10,20 and $50 \mu \mathrm{g} / \mathrm{ml}$ for IRB and CST on three different days. The \% RSD for intra-day precision was found to be 0.06$0.61,0.34-0.54$ and $0.02-0.08$ respectively for HTZ, IRB and CST. Whereas the \% RSD for inter-day precision was found to be 0.65 1.32, 0.61-1.25 and 0.24-1.19 for HTZ, IRB and CST respectively (Table 7).

\section{Accuracy}

The method accuracy was proved by the recovery test at three different concentrations $(80,100$ and $120 \%$ ) for all the three drugs. A known amount of standards $(10 \mu \mathrm{g} / \mathrm{ml})$ were added to sample solutions and then further diluted to achieve the total concentrations of 18,20 and $22 \mu \mathrm{g} / \mathrm{ml}$ for all the three drugs as described in Table 7. The \% recovery for HTZ, IRB and CST was found to be 98.23-99.12, 98.88-99.79 and 98.78-99.02 respectively with \%RSD with in acceptance criteria $(<2.0 \%)$.

Table 7: Precision and accuracy studies of HTZ, IRB and CST.

\begin{tabular}{|c|c|c|c|c|c|c|c|c|}
\hline \multirow[b]{2}{*}{ Analyte } & \multirow[b]{2}{*}{$\begin{array}{l}\text { Conc. }(\mu \mathrm{g} \\
\left.\mathrm{mL}^{-1}\right)\end{array}$} & \multicolumn{3}{|c|}{ Intra-Day Precision } & \multicolumn{4}{|c|}{ Inter-Day Precision } \\
\hline & & $\begin{array}{c}\text { *Measured conc. }(\mu \mathrm{g} \\
\left.\mathrm{mL}^{-1}\right) \\
\pm \mathrm{SD}\end{array}$ & $\%$ RSD & SEM & & $\begin{array}{l}\text { ed } \\
\text { mL }\end{array}$ & $\%$ RSD & SEM \\
\hline \multirow{3}{*}{ HTZ } & 5 & $5.02 \pm 0.03$ & 0.61 & 0.0177 & \multicolumn{2}{|c|}{$4.93 \pm 0.06$} & 1.32 & 0.0375 \\
\hline & 10 & $10.00 \pm 0.01$ & 0.08 & 0.0046 & \multicolumn{2}{|c|}{$9.89 \pm 0.11$} & 1.10 & 0.0629 \\
\hline & 20 & $20.00 \pm 0.01$ & 0.06 & 0.0065 & \multicolumn{2}{|c|}{$19.90 \pm 0.13$} & 0.65 & 0.0751 \\
\hline \multirow{3}{*}{ IRB } & 10 & $9.82 \pm 0.04$ & 0.45 & 0.0257 & \multicolumn{2}{|c|}{$9.87 \pm 0.12$} & 1.25 & 0.0715 \\
\hline & 20 & $19.54 \pm 0.10$ & 0.54 & 0.0606 & \multicolumn{2}{|c|}{$19.86 \pm 0.13$} & 0.66 & 0.0752 \\
\hline & 50 & $49.73 \pm 0.17$ & 0.34 & 0.0981 & \multicolumn{2}{|c|}{$49.67 \pm 0.30$} & 0.61 & 0.1760 \\
\hline \multirow{3}{*}{ CST } & 10 & $10.03 \pm 0.01$ & 0.08 & 0.0046 & \multicolumn{2}{|c|}{$9.88 \pm 0.12$} & 1.19 & 0.0678 \\
\hline & 20 & $20.02 \pm 0.01$ & 0.02 & 0.0025 & \multicolumn{2}{|c|}{$19.83 \pm 0.15$} & 0.77 & 0.0879 \\
\hline & 50 & $50.01 \pm 0.02$ & 0.05 & 0.0138 & \multicolumn{2}{|c|}{$49.86 \pm 0.12$} & 0.24 & 0.0688 \\
\hline \multicolumn{9}{|c|}{ Accuracy Studies } \\
\hline Analyte & $\begin{array}{l}\text { Spiked Conc. } \\
\qquad\left(\mu \mathrm{g} \mathrm{mL}^{-1}\right)\end{array}$ & $\begin{array}{c}\text { Total Theoretical } \\
\text { conc. } \\
\left(\mu \mathrm{g} \mathrm{mL}^{-1}\right)\end{array}$ & $\begin{array}{c}* \text { Conc. Found ( } \mu \mathrm{g} \\
\left.\mathrm{mL}^{-1}\right) \\
\pm \mathrm{SD}\end{array}$ & $\% \mathrm{R}$ & & SE & & $\%$ Recovery \\
\hline \multirow{3}{*}{ HTZ } & $4(80 \%)$ & 9 & $8.85 \pm 0.0318$ & \multicolumn{2}{|c|}{0.36} & \multicolumn{2}{|c|}{0.2042} & 98.31 \\
\hline & $5(100 \%)$ & 10 & $9.91 \pm 0.0810$ & \multicolumn{2}{|c|}{0.82} & \multicolumn{2}{|c|}{0.4677} & 99.12 \\
\hline & $6(120 \%)$ & 11 & $10.81 \pm 0.0889$ & \multicolumn{2}{|c|}{0.82} & \multicolumn{2}{|c|}{0.4668} & 98.23 \\
\hline \multirow{3}{*}{ IRB } & $8(80 \%)$ & 18 & $17.80 \pm 0.0602$ & 0.3 & & 0.19 & & 98.88 \\
\hline & $10(100 \%)$ & 20 & $19.96 \pm 0.0496$ & 0.2 & & 0.14 & & 99.79 \\
\hline & $12(120 \%)$ & 22 & $21.85 \pm 0.0305$ & 0.1 & & 0.08 & & 99.34 \\
\hline & $8(80 \%)$ & 18 & $17.78 \pm 0.0422$ & 0.2 & & 0.13 & & 98.78 \\
\hline $\mathrm{CST}$ & $10(100 \%)$ & 20 & $19.80 \pm 0.0644$ & 0.3 & & 0.18 & & 99.02 \\
\hline & $12(120 \%)$ & 22 & $21.74 \pm 0.0193$ & 0.0 & & 0.05 & & 98.83 \\
\hline
\end{tabular}

*Mean of triplet replicates 


\section{Robustness}

The robustness of an analytical procedure is referred as the method's ability to retain unaffected even by small variations in parameters from the original conditions and there by proves the ability of its reliability for routine analysis. The detection wavelength was set at 223 and $227 \mathrm{~nm}( \pm 2 \mathrm{~nm})$, the ratio of percentage of $0.1 \%$ acetic acid: acetonitrile in the mobile phase was applied as 25:75 and 21:79 $( \pm 2, \mathrm{v} / \mathrm{v})$, the flow rate was set at 0.6531 and $0.8531 \mathrm{ml} / \mathrm{min}( \pm 0.1 \mathrm{ml} / \mathrm{min})$. The results obtained for the robustness study were shown in Table 8. From the results it was shown that the retention times and the assays for the test solutions were not much affected by varying the conditions and were in consonance with the results for original conditions. The
$\%$ RSD value of assay of the sample under original conditions and robustness conditions was less than $2.0 \%$ (i.e., $0.018-0.322$ for $\mathrm{R}_{\mathrm{t}}$ and for assay it is 0.0292-0.2152) indicating that the method is robust.

\section{Analysis of commercial formulations}

The proposed method was applied to the available marketed formulations i.e., IROVEL- $\mathrm{H}^{\circledR}$ (label claim: $150 \mathrm{mg} / 12.5 \mathrm{mg}$ of IRB/ HTZ), and CANDESAR- ${ }^{\circledR}$ (label claim: $16 \mathrm{mg} / 12.5 \mathrm{mg}$ of CST/ HTZ). The \% recovery was found to be $97.69-98.37 \%$ for HTZ, $98.47 \%$ for IRB and $98.51 \%$ for CST (Table 8). The resultant chromatograms obtained for marketed formulations were shown in Figure 8.

Table 8: Robustness Studies of HTZ, IRB and CST.

\begin{tabular}{|c|c|c|c|c|c|c|c|}
\hline $\begin{array}{l}\text { Parameter } \\
\text { (Condition) }\end{array}$ & Analyte & $* \%$ Assay \pm SD & $\%$ RSD & SEM & $\begin{array}{c}* \text { Retention Time } \\
\pm \text { SD }\end{array}$ & $\%$ RSD & SEM \\
\hline \multicolumn{8}{|c|}{ Mobile Phase Flow Rate $\left( \pm 0.1 \mathrm{~mL} \cdot \mathrm{min}^{-1}\right)$} \\
\hline \multirow{3}{*}{$\left(0.6531 \mathrm{~mL} \cdot \mathrm{min}^{-1}\right)$} & HTZ & $98.96 \pm 0.0557$ & 0.0563 & 0.0322 & $2.019 \pm 0.007$ & 0.322 & 0.0038 \\
\hline & IRB & $98.36 \pm 0.1810$ & 0.1840 & 0.1045 & $3.844 \pm 0.003$ & 0.084 & 0.0019 \\
\hline & CST & $98.48 \pm 0.0351$ & 0.0356 & 0.0202 & $8.594 \pm 0.003$ & 0.029 & 0.0015 \\
\hline \multirow{3}{*}{$\left(0.8531 \mathrm{~mL} \cdot \mathrm{min}^{-1}\right)$} & HTZ & $99.34 \pm 0.111$ & 0.1120 & 0.0642 & $1.922 \pm 0.005$ & 0.235 & 0.0026 \\
\hline & IRB & $101.19 \pm 0.1006$ & 0.0994 & 0.0581 & $3.672 \pm 0.002$ & 0.042 & 0.0009 \\
\hline & CST & $100.20 \pm 0.063$ & 0.0627 & 0.0363 & $8.354 \pm 0.004$ & 0.042 & 0.0020 \\
\hline \multicolumn{8}{|c|}{ Detection Wavelength $( \pm 2 \mathrm{~nm})$} \\
\hline \multirow{3}{*}{$(223 \mathrm{~nm})$} & HTZ & $100.34 \pm 0.029$ & 0.0292 & 0.0169 & $1.985 \pm 0.003$ & 0.154 & 0.0018 \\
\hline & IRB & $101.94 \pm 0.0436$ & 0.0427 & 0.0251 & $3.733 \pm 0.002$ & 0.056 & 0.0012 \\
\hline & CST & $100.80 \pm 0.215$ & 0.2128 & 0.1239 & $8.483 \pm 0.002$ & 0.025 & 0.0012 \\
\hline \multirow{3}{*}{$(227 \mathrm{~nm})$} & HTZ & $98.53 \pm 0.076$ & 0.0774 & 0.0440 & $1.985 \pm 0.003$ & 0.127 & 0.0015 \\
\hline & IRB & $98.48 \pm 0.0546$ & 0.0555 & 0.0315 & $3.731 \pm 0.003$ & 0.086 & 0.0019 \\
\hline & CST & $99.32 \pm 0.068$ & 0.0686 & 0.0393 & $8.483 \pm 0.002$ & 0.025 & 0.0012 \\
\hline \multicolumn{8}{|c|}{ Mobile Phase Composition $( \pm 2 \%$ Acetonitrile, $v / v$ ) } \\
\hline \multirow{3}{*}{$(25: 75, v / v)$} & HTZ & $99.98 \pm 0.140$ & 0.1397 & 0.0807 & $1.995 \pm 0.002$ & 0.077 & 0.0009 \\
\hline & IRB & $100.15 \pm 0.1444$ & 0.1441 & 0.0833 & $3.823 \pm 0.002$ & 0.040 & 0.0009 \\
\hline & CST & $9953 \pm 0.120$ & 0.1210 & 0.0695 & $8.484 \pm 0.002$ & 0.018 & 0.0009 \\
\hline \multirow{3}{*}{$(21: 79, v / v)$} & HTZ & $99.90 \pm 0.191$ & 0.1909 & 0.1101 & $1.973 \pm 0.004$ & 0.183 & 0.0021 \\
\hline & IRB & $99.45 \pm 0.2140$ & 0.2152 & 0.1236 & $3.682 \pm 0.002$ & 0.041 & 0.0009 \\
\hline & CST & $101.06 \pm 0.103$ & 0.1022 & 0.0596 & $8.472 \pm 0.002$ & 0.018 & 0.0009 \\
\hline
\end{tabular}

*Mean of triplet replicates. 


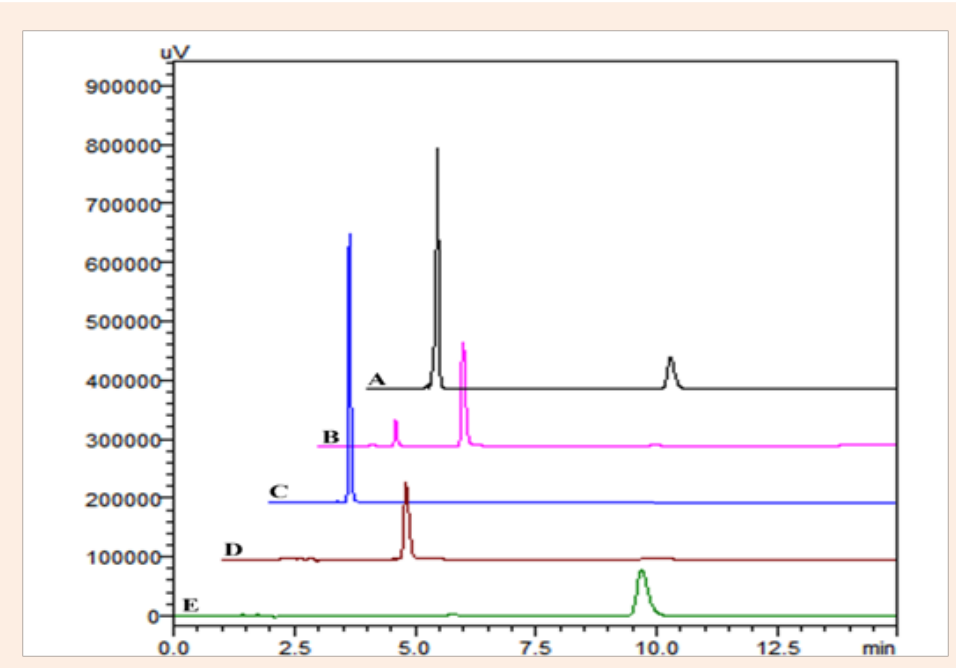

Figure 8: Typical chromatograms [A] CANDESAR-H ${ }^{\circledR},[\mathrm{B}]$ IROVEL- $^{\circledR},[\mathrm{C}] \mathrm{HTZ}(10 \mu \mathrm{g} / \mathrm{ml}),[\mathrm{D}] \mathrm{IRB}(10 \mu \mathrm{g} / \mathrm{ml})$ and $[\mathrm{E}]$ CST $(10 \mu \mathrm{g} / \mathrm{ml})$.

\section{Conclusion}

A simple isocratic RP-HPLC method for simultaneous determination of HTZ, IRB and CST in bulk and markedly available pharmaceutical dosage form was developed. For this central composite design which is a response surface methodology was adapted to spot out the significant impact of the independent variables such as $\%$ organic phase and the flow rate each at triplet levels on the chromatographic responses. The chromatographic responses such at the resolution, theoretical plates, tailing factor and total analysis time were simultaneously optimized with the backing of design of experiments methodology. This multivariate chemometric assisted experimental method development and its validation emphasizes that systematic approach for quality leads to creation of highly budgetary and conscientious chromatographic methods.

\section{Acknowledgement}

The authors are grateful to University Grants Commission, New Delhi for their financial support, Sun Pharmaceutical Industries Ltd., (India) for providing the gift samples and M/s GITAM University, Visakhapatnam for providing the research facilities.

\section{References}

1. WHO (2013) A global brief on hypertension: Silent killer, global public health crisis. World Health Organization, Geneva, Switzerland.

2. Mancia G1, De Backer G, Dominiczak A, Cifkova R, Fagard R, et al. (2007) 2007 Guidelines for the management of arterial hypertension: The Task Force for the Management of Arterial Hypertension of the European Society of Hypertension (ESH) and of the European Society of Cardiology (ESC). J Hypertens 28(12): 1462-1536.

3. Gerard A McKay, John L Reid, Matthew R Walters (2013) Lecture Notes: Clinical Pharmacology and Therapeutics, ( $9^{\text {th }}$ edn), WileyBlackwell John Wiley \& Sons, Hoboken, UK.

4. Vander Heyden Y1, Nijhuis A, Smeyers-Verbeke J, Vandeginste BG, Massart DL (2001) Guidance for Robustness: Ruggedness Tests in
Method Validation. J Pharm Biomed Anal 24(5): 723-753.

5. Altekar M, Homon CA, Kashem Md A, Mason SW, Nelson RM, et al, (2007) Assay Optimization: A Statistical Design of Experiments Approach. Clin Lab Med 27(1): 139-154.

6. Lewis EJ, Hunsicker LG, Clarke WR, Berl T, Pohl MA, et al. (2010) Reno protective effect of the angiotensin-receptor antagonist Irbesartan in patients with nephropathy due to type 2 diabetes. $\mathrm{N}$ Engl J Med 345(12): 851-860.

7. (2006) Whitehouse Station. (14 ${ }^{\text {th }}$ edn), Merck Research Laboratories Division of Merck and Co., Inc., New Jersey, USA.

8. Beermann B, Groschinsky-Grind M, Rosen A (1976) Absorption, metabolism, and excretion of Hydrochlorothiazide. Clin Pharmacol Ther 19(5): 531-537.

9. Ganesan M, Nanjundan S, Gomathi M, Muralidharan S (2010) Method development and validation of Irbesartan using LCMS/MS: application to pharmacokinetic studies. Journal of Chemical and Pharmaceutical Research 2(4): 740-746.

10. Tutunji LF, Tutunji MF, Alzoubi MI, Khabbas MH, Arida AI (2010) Simultaneous determination of Irbesartan and Hydrochlorothiazide in human plasma using HPLC coupled with tandem mass spectrometry: application to bioequivalence studies. J Pharm Biomed Anal 51(4): 985-990.

11. Xiangjun Qiu, Zhe Wang, Bing Wang, Hui Zhan, Xiaofeng Pan, et al. (2014) Simultaneous determination of Irbesartan and Hydrochlorothiazide inhuman plasma by ultra-high performance liquid chromatography tandem mass spectrometry and its application to a bioequivalence study. Journal of Chromatography B 957: 110-115.

12. Raja B, Himasri P, Ramadevi B (2012) RP-HPLC Method for the Simultaneous estimation of Irbesartan and Hydrochlorothiazide in pharmaceutical dosage form. International Research Journal of Pharmaceutical and Applied Sciences 2(3): 29-38.

13. Zorica Vujic, Nedzad Mulavdic, Miralem Smajic, Jasmina Brboric, Predrag Stankovic (2012) Simultaneous analysis of Irbesartan and Hydrochlorothiazide: An Improved HPLC method with the aid of a chemometric protocol. Molecules 17: 3461-3474. 
14. Ibrahim A, Amer M Alanazi, Ali S Abdelhameed, Nasr Y Khalil, Azmat A Khan Darwish (2014) HPLC method with monolithic column for simultaneous determination of Irbesartan and Hydrochlorothiazide in tablets. Acta Pharm 64(2): 187-198.

15. Rane VP, Patil KR, Sangshetti JN, Yeole RD, Shinde DB (2010) Stability indicating LC method for simultaneous determination of Irbesartan and Hydrochlorothiazide in pharmaceutical preparations. J Chromatogr Sci 48(7): 595-600.

16. Milind B Ubale, Vitthal D Dhakane, Vilas R Chaudhari (2012) Simultaneous high performance liquid chromatography of Irbesartan and Hydrochlorothiazide in pharmaceutical dosage form. Journal of Pharmaceutical and Scientific Innovation 1(1): 25-28.

17. Ramachandran D, Mogili Reddy D, Purnachandra Rao P (2014) Method development and validation for the simultaneous estimation of Hydrochlorothiazide and Irbesartan in a pharmaceutical formulation by RP-HPLC method. International Journal of Research in Pharmaceutical and Nano Sciences 3(5): 482-490.

18. Mohammed EAH, Mohamed A Abu El-Enin, Dina T El-Sherbiny, Dalia R ElW, Saadia M ElA (2013) Simultaneous determination of Irbesartan and Hydrochlorothiazide in pharmaceutical preparations and spiked human plasma using micro emulsion liquid chromatography. International Journal of Advances in Pharmaceutical Research 4(7): 1944-1959.

19. Rosangluai, Shanmugasundaram P, Malarkodi Velraj. (2011) Validated HPTLC method for simultaneous estimation of Irbesartan and Hydrochlorothiazide in a tablet dosage form. Der Pharma Chemica 3(5): 310-317.

20. Abd EL-Aziz O, Farouk M, Hemdanb A, Shehata M (2011) Simple Novel Spectrophotometric and Spectrofluorometric methods for determination of some Anti-hypertensives. The Journal of American Science 7(1): 300-312.

21. Piusha Shakya, Pushpendra Kumar Jain, Srivastava SP, Asmitagajbhiye (2015) Simultaneous estimation of Irbesartan and Hydrochlorothiazide by UV spectroscopy. International Journal of Pharmacy and Pharmaceutical Sciences 7(6): 389-391.

22. Patel Kaushik R, Patel Satish A, Darji Vinay C, Sonal Rakshit N (2011) Simultaneous spectrophotometric estimation of Irbesartan and Hydrochlorothiazide in tablets. International Research Journal of Pharmacy 2(3): 202-207.

23. Sridharan D, Thenmozhi A, Rajamanickam V, Sundaranandavalli S, Palanikumar B (2010) Simultaneous estimation of Irbesartan and Hydrochlorothiazide in combined pharmaceutical dosage form by UV spectroscopy using multicomponent mode of analysis. International Journal of ChemTech Research 2(2): 876-879.

24. Divya K, Sruthi V, Sravan KG, Sanayaima H, Akiful HM (2014) Simultaneous estimation of Irbesartan and Hydrochlorothiazide in combined pharmaceutical dosage form by UV spectroscopy. The International Journal of Innovative Pharmaceutical Sciences and Research 2(8): 1674-1680.

25. Lakshmi S, Lakshmi KS (2014) H-point standard addition method for simultaneous spectrophotometric determination of Irbesartan, Hydrochlorothiazide and Telmisartan in tablets. International journal of research in pharmacy and chemistry 4(2): 373-380.

26. Mathrusri AM, Sai Phani KJ (2015) New Spectrophotometric Methods for the Simultaneous Determination of Irbesartan and Hydrochlorothiazide in Combined Dosage Forms. Pharmaceutical Methods 6(3): 120-125.
27. Bipin HM, Sachin BM (2008) HPTLC-Densitometric analysis of Candesartan Cilexetil and Hydrochlorothiazide in Tablets. Journal of Planar Chromatography 21(3): 173-176.

28. Vijaya BD, Kishore KH, Pankaj KC, Satyanarayana V, Venkateswarlu V (2012) LC-MS/MS method for simultaneous estimation of Candesartan and Hydrochlorothiazide in human plasma and its use in clinical pharmacokinetics. Bioanalysis 4(10): 1195-1204.

29. Bhupinder Singh, Rama S. Lokhandae, Ashish Dwivedi, Sandeep Sharma \& Naveen Dubey. (2014) Improved simultaneous quantitation of Candesartan and Hydrochlorothiazide in human plasma by UPLCMS/MS and its application in bioequivalence studies. Journal of Pharmaceutical Analysis 4(2): 144-152.

30. Mani K, Seshagiri RJVLN (2014) Standardization and stability indicating studies by RP-HPLC method for the simultaneous estimation of Candesartan Cilexetil \& Hydrochlorothiazide in tablet dosage form. International Journal of Pharmaceutical Sciences and Research 5(12): 5438-5446.

31. Nevin E (2003) Simultaneous analysis of Candesartan Cilexetil and Hydrochlorothiazide in human plasma and dosage forms using HPLC with a photodiode array detector. Journal of Liquid Chromatography \& Related Technologies 26(15): 2581-2591.

32. LEI, Jian, Zhang, Xiao-Song, Zhuo Z, Kai Z, et al. (2007) HPLCUV simultaneous determination of Candesartan Cilexetil and Hydrochlorothiazide in compound Candesartan Cilexetil tablets. Chinese Journal of Pharmaceutical Analysis 27(4): 566-568.

33. Rama JVE, Gopichand INTI, Venkatasubramanian J, Sudhakar RV, Sreeramulu J (2014) New stability indicating method for quantification of impurities in Candesartan Cilexetil and hydrochlorothiazide tablets by validated HPLC. International Journal for Pharmaceutical Research Scholars 3(2): 100-112.

34. Mathrusri AM, Narendra A, Ravi KK (2012) Liquid chromatographic method for the simultaneous quantitative determination of Candesartan Cilexetil and Hydrochlorothiazide in pharmaceutical dosage forms. Journal of Drug Delivery \& Therapeutics 2(2): 48-54.

35. Ananda RB, Surya KTAD (2013) Development and validation of a RPHPLC method for estimation of Hydrochlorothiazide and Candesartan Cilexetil in pharmaceutical dosage form. International Journal of Pharmaceutics 3(1): 166-169.

36. Rahul Raut, Narayanaswamy VB (2015) Development of RP-HPLC method for the simultaneous estimation of Candesartan Cilexetil and Hydrochlorothiazide in pharmaceutical dosage forms. International journal of research in pharmacy and chemistry 5(3): 452-469.

37. Qutab SS, Razzaq SN, Ashfaq M, Shuja ZA, Khan IU (2007) Simple and sensitive LC-UV method for simultaneous analysis of Hydrochlorothiazide and Candesartan Cilexetil in pharmaceutical formulations. Acta Chromatographica 19: 119-129.

38. Veeranjaneyulu D, Aneesha A, Nandakishore A (2013) Stability indicating RP-HPLC method for the simultaneous determination of Candesartan Cilexetil and hydrochlorothiazide in bulk and dosage forms. Indian Journal of Research in Pharmacy and Biotechnology 1(5): 720-724.

39. Alaa E Khedr (2008) Simultaneous Determination of Candesartan Cilexetil and Hydrochlorothiazide by High Performance Liquid Chromatography. Journal of King Abdulaziz University Medical Sciences 15(2): 3-13.

40. Dhia Eldin A, Elmagied E, Omer AA, Mohammed BM (2015) RP-HPLC 
method development and validation for simultaneous estimation of Candesartan Cilexetil and Hydrochlorothiazide tablet dosage form. American Journal of PharmTech Research 5(3): 248-258.

41. Mathrusri AM, Sai Phani KJ (2015) Simultaneous Spectrophotometric Estimation of Candesartan Cilexetil and Hydrochlorothiazide in Tablet Dosage Form. Pharmaceutical Methods 6(3): 148-151.

42. Wedad AAO, Hany WD, Nawal AAA, Amina MAB (2013) Application of PCR and PLS methods for the simultaneous determination of Candesartan Cilexetil and Hydrochlorothiazide in their pharmaceutical preparations. Digest journal of nanomaterials and biostructures 8(3): 1253-1262.
43. Jignesh P, Dave JB, Patel CN, Patel D (2010) Q-Analysis spectrophotometric methods for estimation of Candesartan Cilexetil and Hydrochlorothiazide in tablet dosage form. Journal of Chemical and Pharmaceutical Research 2(3): 10-14.

44. Bhadke TK, Mohite SK, Magdum CS (2012) Simultaneous Estimation of Candesartan Cilexetil and Hydrochlorothiazide in Tablet Dosage Form by UV spectrophotometric Method. International Journal of PharmTech Research 4(2): 786-790.

45. ICH (2005) Q2 (R1): validation of analytical procedures: text and methodology. International Conference on Harmonization, USA. 